\title{
Warming shortens flowering seasons of tundra plant communities
}

Prevéy, Janet S.; Rixen, Christian; Rüger, Nadja; Høye, Toke T.; Bjørkman, Anne D.; MyersSmith, Isla H.; Elmendorf, Sarah C.; Ashton, Isabel W.; Cannone, Nicoletta; Chisholm, Chelsea Lee; Clark, Karin; Cooper, Elisabeth J.; Elberling, Bo; Fosaa, Anna Maria; Henry, Greg H. R.; Hollister, Robert D.; Jónsdóttir, Ingibjörg Svala; Klanderud, Kari; Kopp, Christopher W.; Lévesque, Esther; Mauritz, Marguerite; Molau, Ulf; Natali, Susan M.;

Oberbauer, Steven F.; Panchen, Zoe A.; Post, Eric; Rumpf, Sabine B.; Schmidt, Niels Martin; Schuur, Edward; Semenchuk, Philipp R.; Smith, Jane G.; Suding, Katharine N.; Totland, Ørjan; Troxler, Tiffany; Venn, Susanna; Wahren, Carl-Henrik; Welker, Jeffrey M.; Wipf, Sonja Published in:

Nature Ecology \& Evolution

DOI:

10.1038/s41559-018-0745-6

Publication date:

2019

Document version

Peer reviewed version

Citation for published version (APA):

Prevéy, J. S., Rixen, C., Rüger, N., Høye, T. T., Bjørkman, A. D., Myers-Smith, I. H., Elmendorf, S. C., Ashton, I. W., Cannone, N., Chisholm, C. L., Clark, K., Cooper, E. J., Elberling, B., Fosaa, A. M., Henry, G. H. R., Hollister, R. D., Jónsdóttir, I. S., Klanderud, K., Kopp, C. W., ... Wipf, S. (2019). Warming shortens flowering seasons of tundra plant communities. Nature Ecology \& Evolution, 3(1), 45-52. https://doi.org/10.1038/s41559-018-0745-6 
This document is the accepted manuscript version of the following article:

Prevéy, J. S., Rixen, C., Rüger, N., Høye, T. T., Bjorkman, A. D., Myers-Smith, I. H., ... Wipf, S. (2019). Warming shortens flowering seasons of tundra plant communities. Nature Ecology \& Evolution, 3, 45-52.

https://doi .org/10.1038/s41559-018-0745-6

1 Classification: Biological Sciences, Ecology

2 Title: Warming shortens flowering seasons of tundra plant communities

Running head: Warming shortens flowering seasons

Authors: Janet S. Prevéy ${ }^{* 1,2}$, Christian Rixen ${ }^{2}$, Nadja Rüger ${ }^{3,4}$, Toke T. Høye ${ }^{5}$, Anne D. Bjorkman $^{6,7}$, Isla H. Myers-Smith ${ }^{8}$, Sarah C. Elmendorf, ${ }^{9,10}$, Isabel W. Ashton ${ }^{11}$, Nicoletta Cannone $^{12}$, Chelsea Chisholm ${ }^{13,2}$, Elisabeth J. Cooper ${ }^{14}$, Bo Elberling ${ }^{15}$, Anna Maria Fosaa ${ }^{16}$, Greg H.R. Henry ${ }^{17}$, Robert D. Hollister ${ }^{18}$, Ingibjörg Svala Jónsdóttir ${ }^{19}$, Kari Klanderud ${ }^{20}$, Christopher W. Kopp ${ }^{21}$, Esther Lévesque ${ }^{22}$, Marguerite Mauritz ${ }^{23}$, Ulf Molau ${ }^{24}$, Susan Natali $^{25}$, Steve Oberbauer ${ }^{26}$, Zoe A. Panchen ${ }^{27}$, Eric Post ${ }^{28}$, Sabine B. Rumpf ${ }^{29}$, Niels Martin Schmidt $^{5}$, Edward Schuur ${ }^{30}$, Philipp R. Semenchuk ${ }^{29,14}$, Jane G. Smith ${ }^{31}$, Katharine N. Suding ${ }^{10,31}$, Ørjan Totland ${ }^{32}$, Tiffany Troxler ${ }^{26}$, Susanna Venn ${ }^{33}$, Carl-Henrik Wahren ${ }^{34}$, Jeffrey M. Welker ${ }^{35,36}$, Sonja Wipf ${ }^{2}$

\section{Author affiliations:}

1. Pacific Northwest Research Station, USDA-Forest Service, 3625 93rd Avenue SW, Olympia, Washington 98512

2. WSL Institute for Snow and Avalanche Research SLF, 7260 Davos, Switzerland

3. German Centre for Integrative Biodiversity Research (iDiv) Halle-Jena-Leipzig, Deutscher Platz 5e, 04103 Leipzig, Germany

4. Smithsonian Tropical Research Institute, Apartado 0843-03092, Balboa, Ancón, Panama

5. Department of Bioscience and Arctic Research Centre, Aarhus University, Denmark

6. Ecoinformatics \& Biodiversity, Department of Bioscience, Aarhus University, Denmark

7. Senckenberg Gesellschaft für Naturforschung, Biodiversity and Climate Research Centre (BiK-F), Frankfurt am Main, Germany

8. University of Edinburgh, Scotland

9. National Ecological Observatory Network, 1685 38th Street, Suite 100, Boulder, Colorado 80301, USA.

10. Department of Ecology and Evolutionary Biology, University of Colorado, Boulder, Colorado 80309, USA.

11. Northern Great Plains Inventory and Monitoring Network, National Park Service, Rapid City, SD, USA

12. Department of Science and High Technology, Università degli Studi dell'Insubria, Como, Italy

13. Center for Macroecology, Evolution and Climate, Natural History Museum of Denmark, Universitetsparken 15, DK-2100 Copenhagen

14. Institute for Arctic and Marine Biology, The Arctic University of Norway, N-9037

Tromsø, Norway

15. Center for Permafrost (CENPERM), Department of Geosciences and Natural

Resource Management, University of Copenhagen, Copenhagen, Denmark

16. Faroese Museum of Natural History, Faroe Islands

17. Department of Geography, University of British Columbia, Vancouver, BC, Canada

18. Biology Department, Grand Valley State University, 1 Campus Drive, Allendale, MI 49401, USA

19. School of Engineering and Natural Sciences, University of Iceland, Iceland

20. Department of Ecology and Natural Resources, Norwegian University of Life Sciences, Norway

21. Department of Botany, University of British Columbia, Vancouver, BC, Canada 
22. Université du Québec à Trois-Rivières, Québec, Canada

23. Center for Ecosystem Science and Society Center, Northern Arizona University, Flagstaff, AZ, USA

24. Department of Biology and Environmental Sciences, University of Gothenburg, Sweden 25. Woods Hole Research Center, Falmouth, MA, USA

26. Department of Biological Sciences, Florida International University, FL, USA

27. Department of Biology, Dalhousie University, Canada

28. Department of Wildlife, Fish, \& Conservation Biology, University of California, Davis

29. Department of Botany and Biodiversity Research, University of Vienna, Rennweg 14, 1030 Vienna, Austria

30. Center for Ecosystem Science and Society Center, Northern Arizona University, Flagstaff, AZ, USA

31. Institute for Arctic and Alpine Research, University of Colorado, Boulder, CO, USA

32. Department of Biology, University of Bergen, Bergen, Norway

33. Centre for Integrative Ecology, School of Life and Environmental Sciences, Deakin University, Victoria, Australia 3125

34. Research Centre for Applied Alpine Ecology, La Trobe University, Bundoora 3086, Australia 35. UArctic and University of Oulu, Finland

36. Department of Biological Sciences, University of Alaska Anchorage, AK, USA

*Corresponding author details: Janet Prevéy, +1 360-701-6466, jprevey@fs.fed.us

Keywords: climate change, ITEX, open-top chambers, phenology, tundra

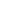

74

75

76

\section{7}

\section{8} 79 80 81 82 


\section{Abstract}

Advancing phenology is one of the most visible effects of climate change on plant communities, and has been especially pronounced in temperature-limited tundra ecosystems. However, phenological responses have been shown to differ greatly between species, with some species shifting phenology more than others. We analyzed a database of 42,689 tundra plant phenological observations to show that warmer temperatures are leading to a contraction of community-level flowering seasons in tundra ecosystems due to a greater advancement in flowering times of late-flowering species than of early-flowering species. Shorter flowering seasons with a changing climate have the potential to alter trophic interactions in tundra ecosystems. Interestingly, these findings differ from those of warmer ecosystems, where early flowering species have been found to be more sensitive to temperature change, suggesting that community-level phenological responses to warming can vary greatly between biomes.

\section{Main}

Warmer temperatures associated with climate change have advanced the phenology of organisms around the world ${ }^{1-3}$, and both temperature increases and phenological changes have been especially pronounced in temperature-limited tundra ecosystems ${ }^{4-7}$. Tundra ecosystems encompass cold regions above latitudinal treeline (Arctic tundra) or altitudinal treeline (alpine tundra). Remote sensing studies indicate broad patterns of changing seasonality of vegetation productivity at high latitudes over time in relation to climate warming ${ }^{8-10}$, however, phenological responses to warmer temperatures have been shown to differ greatly among species and locations, with some species shifting dates of flowering and flower senescence more than others ${ }^{11-15}$. Studies from temperate ecosystems have found that early-flowering species often advance phenological events more in response to warmer temperatures than later-flowering species ${ }^{16,1,17-19}$, however, to date, the relationship between 
flowering time and phenological sensitivity has not been tested across high-altitude tundra ecosystems.

Evidence suggests that across northern tundra ecosystems, phenology of plants from colder sites at higher latitudes changes more with warmer temperatures than phenology of plants from warmer, more southern latitudes ${ }^{7,15,20}$. However, within tundra plant communities, phenological responses to warming are often species-specific, with no clear responses of specific functional groups ${ }^{21-27,3}$ or phylogenetic relationships ${ }^{28}$. A better understanding of the drivers of variation in phenological sensitivity will help determine how species and plant communities will respond to climate change in the future ${ }^{23,29,3}$, as well as contribute to our understanding of the adaptive nature of species-specific phenological responses to climate change.

The timing of life history events, such as flowering, is of critical importance in harsh tundra ecosystems, and the fitness consequences of different phenological responses to climatic drivers can be substantial ${ }^{30,31}$. Plants that track snowmelt dates and not temperature (or thermal sums) may risk exposure to freezing events that can damage flowers and reduce seed production during early snowmelt years ${ }^{32-35}$, whereas plants that flower too late risk not being able to fully develop seeds before the end of the growing season, and may be at a competitive disadvantage to plants that do respond ${ }^{22,36}$.

There are a diversity of life history strategies among species in tundra plant communities, even within the short growing seasons experienced at high latitudes and altitudes $^{21,22,37}$. These various strategies could influence the species-specific responses of plants to warmer temperatures ${ }^{37,38,12}$. The relative flowering time of a species compared to other species in the plant community (hereafter its "phenological niche") could help explain the variation in phenological responses among species in tundra ecosystems. The existence of different phenological niches could promote species coexistence in many ecosystems ${ }^{39-41}$, as phenological niches can strongly influence competitive and trophic interactions ${ }^{42}$. Differential 
shifts in the phenological niche could lead to trophic mismatches in tundra ecosystems, altering food webs and influencing the abundance of pollinators or herbivores ${ }^{43-45,12}$. Classifying organisms using phenological niches could thus be a useful way to predict how species will respond to changes in environmental conditions in the future ${ }^{38}$.

Measuring the relative importance of different environmental cues for Arctic and alpine species, such as temperature and snowmelt date, will help determine how species will respond as the climate warms ${ }^{23,29}$. Although temperature influences the date of snowmelt, snowmelt can be decoupled from temperature because snowmelt is also influenced by the amount and quality of precipitation over winter and spring ${ }^{13}$. The phenology of earlyflowering plant species may be influenced more by photoperiod or the timing of snowmelt, whereas the phenology of late-flowering species is probably more dependent on thermal heat sums accumulated over the growing season ${ }^{22,46}$. If early-flowering tundra species are less responsive to changes in summer temperature than late-flowering ones, then increases in summer temperature will likely accelerate the flowering phenology of late-flowering species more than early-flowering ones. Additionally, if temperatures towards the end of the growing season are rising more rapidly than temperatures at the beginning of the year, then flowering phenology of late-flowering species will advance more than that of early-flowering species ${ }^{14,15}$. In both cases, a more rapid advance of late- than early-flowering species would result in a contraction of the community-level flowering season (Fig. $1,{ }^{12}$, which could substantially change competitive and trophic interactions ${ }^{47,44,12,31}$. In particular, shorter flowering seasons could also strongly limit resource availability for pollinators, especially if the phenology of pollinator species are responding to different drivers than plant communities ${ }^{12,48}$. In this data synthesis, we test how the temperature sensitivity of flowering relates to the phenological niches of tundra species using flowering observations of a total of 253 species, 23 sites, and up to 20 years from Arctic and alpine ecosystems around the world, both from long-term monitoring plots and warming experiments (Fig. 2). With this global dataset, 
we tested three main hypotheses: 1) flowering phenology of late-flowering tundra species is more sensitive to warmer summer temperatures than flowering phenology of early-flowering species. We tested this hypothesis with both observational and experimental data, and hypothesized that: 1a) results would be similar for both observational and experimental data; that is, late-flowering species would be more sensitive to natural and experimental warming. 2) If late-flowering species are flowering earlier, but early-flowering species are not, then the community-level flowering seasons will be shorter in warmer years, and thus, 3) as average summer temperatures at tundra sites have warmed in the recent past, the duration of community-level flowering seasons have decreased over this time period. We examined how the phenological niche of a species influenced the sensitivity of first flowering dates (FFDs) and flower senescence dates (LFDs) to summer temperature indices, snowmelt date, and experimental warming. To test for a contraction of community-level flowering seasons with warmer summers and over time, we compared the community flowering season length to mean June-July temperatures and year for six sites with observations of four or more species over 10 or more years.

\section{Results}

First flowering dates (FFDs) of late-flowering species were more temperature sensitive than early-flowering species (i.e., FFDs of late-flowering species advanced more per ${ }^{\circ} \mathrm{C}$ increase in summer temperature, and in response to experimental warming, than earlyflowering species, Figs. 3A and 4A, Supplementary Fig. 1, Supplementary Table 4). Results of analyses using June temperature for all species, or the average daily temperature from snowmelt through the average flowering date, also indicated a significant influence of phenological niche on temperature sensitivity of flowering (Figs. 3B and 3C, Supplementary Table 4). However, the phenological niche of a species did not influence the sensitivity of FFDs to snowmelt timing (Fig. 3D, Supplementary Table 4). Overall, species from sites with 
colder summer temperatures had greater temperature sensitivity of FFDs (Supplementary

Table 4). Analyses from warming experiments yielded similar results, with greater differences in FFDs between experimentally warmed and control plots for late-flowering species than for early-flowering species (Fig. 4A). There was no influence of phenological niche on the temperature sensitivity of flower senescence dates (LFDs) in either long-term monitoring plots or warming experiments (Supplementary Table 5 and Fig. 4B).

The community-level flowering seasons across the six sites with 10 or more years of data were 3.96 days shorter per $1{ }^{\circ} \mathrm{C}$ warmer June-July temperature $(95 \% \mathrm{CI}=-7.31,-0.79$, Fig. 5A, Supplementary Table 5). The length of the flowering season was estimated as the duration between the average FFD of the earliest and average LFD of the latest flowering species per site in each year. Community-level flowering seasons became shorter over time in all six sites, but the change was significant only at Alexandra Fiord, Daring, and Zackenberg. Across all sites, flowering season length shortened by 0.43 days per year, but the credible interval on this parameter overlapped zero (95\% CIs $=-0.87,0.06$, Fig. 5B). Annual June-July temperatures

\section{Discussion}

Our results reveal an overall shortening of community-level flowering seasons with summer warming across the tundra biome. We additionally found evidence of a contraction of the community-level flowering season over time at a subset of sites. In both cases, the shortening of the flowering season was due to greater temperature sensitivity of flowering of late-flowering than early-flowering species. On average, the temperature sensitivity of first flowering dates was greater for tundra species that flowered later in the growing season compared to those that flowered earlier. This pattern was evident both in long-term monitoring plots over time and in warming experiments. Additionally, observations from long-term monitoring plots indicated that, on average, plants at colder sites were more 
212 phenologically sensitive, consistent with results from Prevéy et al. (2018) using a largely

213 overlapping dataset, and that late-flowering plant species at the coldest tundra sites exhibited

214 the highest phenological sensitivities in the dataset. Our analyses of long-term monitoring and

215 experimental warming data indicate that late-flowering tundra species may alter their

216 flowering phenology more than early-flowering ones in a warmer world, resulting in a

217 shortening of community-level flowering seasons at sites across the tundra biome.

218 The finding of greater temperature sensitivity of late-flowering species differs from

219 results of many studies conducted at lower latitudes and altitudes ${ }^{6,49,18,19}$. Studies from warmer

220 biomes found that early-flowering species often advance phenological events more in

221 response to warmer temperatures than late-flowering species ${ }^{16,1,17-19,50,51}$. Mid- and late-

222 season moisture limitation probably plays a greater role in structuring the phenology of plants

223 in warmer ecosystems ${ }^{52}$. However, in cold tundra ecosystems with relatively short summers,

224 moisture limitation may not be as important a phenological driver as in warmer, drier

225 ecosystems ${ }^{53}$. Additionally, selection might be stronger at the start of the growing season

226 under the harsher climate conditions experienced by early flowering plants in tundra sites

227 relative to more temperature biomes ${ }^{46}$.

228 Our finding of a contraction of the flowering season with warmer temperatures also

229 differs from studies in other ecosystems. Some studies have found a divergence of flowering

230 dates of early- versus late-flowering species with warming in temperate grasslands ${ }^{49}$,

231 montane and subalpine meadows ${ }^{54,55}$, and deserts ${ }^{53}$, with less overlap in the flowering times

232 of species ${ }^{49}$, and a mid-season depression in flower abundance ${ }^{54,55}$. Individual studies

233 conducted in temperate ecosystems and global meta-analyses of phenology experiments and

234 long-term monitoring projects have concluded that early-flowering species are more

235 responsive to climate warming ${ }^{18,6,51}$. However, our results show that Arctic and alpine plants

236 exhibit the opposite pattern, suggesting that community-level phenological responses to

237 warming can vary greatly among biomes ${ }^{19,56}$. 
For the six Arctic sites with over ten years of observations, we documented a

contraction of the flowering season with warmer temperatures, and a trend toward shorter flowering seasons over time, although this pattern was not significant at all sites. A contraction of the flowering season is in agreement with previous single-site studies in arctic ecosystems ${ }^{5,12,48}$. Shorter flowering seasons could lead to possible phenological mismatches if late-season pollinators or herbivores are not following the same cues as late-season plant species ${ }^{48,57}$. Additionally, less dispersion among the flowering times of species in a community may increase competition for pollinators ${ }^{58}$ or, alternatively, increase exposure to more pollinators because plant species are all flowering at similar times ${ }^{59}$. However, it is important to note that we did not directly measure how the abundance of plant species, or the abundance of open flowers, changed with temperature or over time. The timing of peak flowering may shift less than the timing of first flowering dates ${ }^{55}$, thus changes in coverage and abundance of flowers over the season may exhibit different patterns than changes in the overall length of the flowering season ${ }^{60}$.

Increased temperature sensitivity of flowering may be advantageous if it allows plants to track ideal temperature conditions for growth and reproduction ${ }^{61,30}$. Our results suggest that late-flowering species that track temperature more than snowmelt date or photoperiod may be more able to optimize the timing of flowering and could have an advantage as temperature increases or becomes more variable ${ }^{62}$. Phenological plasticity may also be indicative of plasticity of other plant traits, so plant species that can shift phenology to changing conditions may be better able to adjust to climate change over time. To date, there have been few studies comparing phenological traits to other plant traits and changes in plant abundance (but see 30,61). However, as the amount of phenological data available for tundra plant species accumulates, the next logical step will be linking phenological measurements to performance measurements to aid predictions of vegetation change in tundra ecosystems in the future ${ }^{64}$. 

on plant communities ${ }^{2}$, but identifying the underlying mechanisms driving phenological responses to warming is crucial to accurately estimating food-web dynamics and plantpollinator interactions. Our data synthesis demonstrates an agreement between long-term and experimental data to identify how plants respond to warmer temperatures ${ }^{65,66}$. In temperaturelimited tundra ecosystems, late-flowering species advance flowering more in warmer years, and this can lead to a contraction of the flowering season of the entire plant community.

Additionally, these changes are most pronounced at the coldest tundra sites where temperature

272 increases have been greatest ${ }^{20}$. Thus, our study demonstrates that the phenological niches of plant species can be useful predictors of how the flowering of tundra species will respond to warmer temperatures, and can aid predictions of plant and ecosystem responses to climate change in the future.

\section{Methods}

\section{Compilation of the flowering phenology database}

We compiled a database of flowering phenology observations from a total of 253 species at 23 sites in Arctic and alpine ecosystems from both long-term monitoring plots and warming experiments (Supplementary Table 1, Fig. 2). Portions of the dataset were analyzed and reported in Oberbauer et al. (2013) and Prevéy et al. (2017), however, two additional monitoring sites and 10 additional warming experiments are included in this analysis (Supplementary Table 1). Each site collected phenological observations following a standardized protocol that was originally developed for the International Tundra Experiment (ITEX) network ${ }^{67,68}$. Following the ITEX protocol, observers recorded the phenological status of plants one to three times per week over the snow-free season, and specifically recorded the first flowering date (FFD) and last flowering date (LFD) of each species per individual or plot. The FFD was defined as the date when the first flower was open, the first 
pollen was visible, or the first anthers were exposed. The LFD was defined as the date when the withering of anthers, first petal drop, or last petal drop was observed. However, both FFD and LFD were recorded consistently at each site over time. We include data only from longterm monitoring plots that had three or more years of flowering phenology observations per species per plot.

\section{Effects of species phenological niches on the sensitivity of flowering}

We calculated the phenological niche of a species at each site as the average first flowering date of the species at each site across all years of measurements ${ }^{50}$ (Supplementary Table 2). We examined the relationship between phenological niche and temperature (expressed in several ways) and snowmelt dates at long-term monitoring plots. Temperature was expressed as the mean monthly temperature until flowering, mean June temperature, or the mean daily temperature between snowmelt and flowering. Flowering dates for the Southern hemisphere alpine site were adjusted by 210 days to match that of the Northern hemisphere growing season, and to assist with model convergence in analyses. We specified mean monthly temperature until flowering separately for each species and site as the average monthly air-temperature from June through the average month of flowering, except for 29 site by species combinations where species flowered in May, for which we used average May temperature (Supplementary Table 2). For example, if the phenological niche of a species was June $30^{\text {th }}$, then mean June temperature was used as the summer temperature variable for that species. However, if the phenological niche was July $15^{\text {th }}$, then average June-July temperature was used (Supplementary Table 2). To test the influence of the temperature windows on the results we obtained, we also performed the analyses with June temperature as the predictor variable for all sites and species, because preliminary analysis showed that June temperature was the strongest predictor of flowering across all species and sites (Supplementary Table 2). We used average monthly temperatures because they were available for all sites in the 
analyses; thus allowing us to incorporate the largest set of phenological data available. We recognize that using monthly mean temperatures may bias results, as sensitivity of flowering time for species flowering in the early parts of months are obviously not affected by temperatures experienced after they flower. Thus, for the subset of 12 sites with both daily temperature data and snowmelt dates available we calculated the mean daily temperature between snowmelt and flowering as the average daily air temperature from the date of snowmelt through the average date of flowering for each species and year. Finally, we examined the association between the timing of snowmelt and flowering in long-term monitoring plots by comparing the phenological niches of species to snowmelt timing for the subset of 13 sites that had recorded snowmelt dates over time.

Models also included the effect of mean site-level summer temperatures (June-Aug) from 1981-2000 as an additional predictor variable of species phenological responses, since a previous synthesis found that flowering dates of species from colder tundra sites were more sensitive to changes in temperature than those from warmer sites ${ }^{20}$. Mean monthly temperatures for sites were obtained from local weather stations when available. If no longterm (1981-2010) weather data were available near sites, then mean monthly temperatures were estimated using $0.5^{\circ}$ gridded temperature data from the Climate Research Unit (CRU) ${ }^{69}$ (Supplementary Table 1). Temperatures and phenological niches were mean-centered by site for all species for long-term monitoring plot data. Plot within site, and year within site, were included as random variables. We also tested for the interaction between phenological niche and temperature.

In total, the analyses of FFDs with summer temperature windows or mean June temperatures as predictor variables included 14,324 observations from 318 unique site by species combinations at 19 sites. The analyses of FFDs with snowmelt date included 9,918 observations from 141 unique site by species combinations at 13 sites, and the analyses of FFDs using average daily temperatures included 9,713 observations from 143 unique site by 
species combinations at 11 sites. The analyses of LFDs with summer temperature windows or mean June temperatures as predictor variables included 9,226 observations from 88 unique site by species combinations at 11 sites. The analyses of LFDs with snowmelt date included 7,661 observations from 80 unique site by species combinations at 11 sites, and the analyses of LFDs using average daily temperatures included 7,341 observations from 74 unique site by species combinations at 9 sites.

\section{Effects of phenological niches on the temperature sensitivity of flowering in warming experiments}

We examined observations from warming experiments that utilized open-top chambers (OTCs) to investigate how experimental warming influenced the flowering dates of species with different phenological niches. In the warming experiments, plots were warmed with ca. $1 \mathrm{~m}^{2}$ fiberglass or polycarbonate OTCs, in either cone or hexagonal shapes, that increased air temperature by $0.5-3{ }^{\circ} \mathrm{C}^{67,70-72}$, Supplementary Table 3 ). The OTCs were placed on plots either only over the summer, or left on plots year-round, depending on the site (Supplementary Table S3).

To examine how the phenological niche of a species influenced its phenological sensitivity to experimental warming, we first calculated the average difference in the timing of phenological events (either FFD or LFD) between control and experimentally warmed plots at each site and year for every species that occurred in both treatments. Then the phenological niches of each species were compared to the difference in the number of days between the FFD or the LFD in experimentally warmed and control plots for each species, site, and year combination. Mean site-level summer temperature was not included as a predictor variable in the warming experiment analyses because the amount of experimental warming differed between experiments at different sites (Supplementary Table 3). We also examined how differences in the amount of warming in different warming experiments may have altered 
results by calculating the difference in the number of days between the FFDs or the LFDs in experimentally warmed and control plots divided the mean number of degrees of warming reported for chambers at each site or subsite within site (Supplementary Table 3) to get an estimate of the change in flowering date per ${ }^{\circ} \mathrm{C}$ of warming.

In total, the analyses of FFDs in warming experiments included 1219 flowering observations from 164 unique site by species combinations at 16 sites. Analyses of LFDs in warming experiments included 743 observations from 96 unique site by species combinations at 11 sites.

\section{Statistical analyses of effects of phenological niches on sensitivity of flowering}

To statistically analyze phenological observations over the different numbers of sites, years of observations, and species, we used Bayesian hierarchical modeling. This approach allowed for estimation of the uncertainties of phenological responses among sites, plots, years, and species, and the incorporation of these uncertainties in the final correlation of phenological niche and phenological responses per species per site ${ }^{73}$.

For data from long-term monitoring plots, we used two-level regression models. At the lower level, we estimated phenological sensitivities by relating the date of phenological events (FFD or LFD) to temperature or snowmelt date. At the higher (species-) level, we related species' phenological sensitivities to their phenological niches. For data from warming experiments, the difference (in days) of FFD or LFD between warmed and control plots was directly included as a response variable in the species-level regression.

We fit Bayesian models using the program Stan ${ }^{74}$, which was accessed using the package Rstan ${ }^{75}$ in the statistical program R 3.2.2 ${ }^{76}$. Each model was run with 2 chains of 20,000 iterations, using Hamiltonian Monte Carlo (HMC) sampling. We used flat priors for all parameter estimates. Full model details and code are included in S7. We checked for convergence of chains for all parameters both visually with trace plots and with the Gelman- 
395

396

397

398

399

400

401

402

403

404

405

406

407

408

409

410

411

412

413

414

415

416

417

418

419

420

Rubin convergence statistic ${ }^{77}$. Trace plots showed that chains mixed well and converged to stationary distributions for all parameter estimates. Gelman-Rubin convergence statistics for parameter estimates of all models were $<1.02$.

\section{Duration of flowering season}

To test for a contraction of community-level flowering seasons in association with warmer summers, we conducted analyses that only included sites with FFDs and LFDs for four or more species over 10 or more years. This limited analyses to the six Arctic sites with long-term monitoring data: Alexandra Fiord, Atqasuk, Utqiagivik, Daring Lake, Toolik Lake, and Zackenberg. Flower count or peak flowering data were not available for all sites, so we used a proxy for the community flowering season calculated as the number of days between the average FFD of the earliest flowering species at a site per year and the average LFD of the latest flowering species at a site per year. We used the earliest and latest flowering species in each year to avoid any bias caused by uneven shifts in flowering times among species.

Although changes in first and last flowering dates are not always representative of changes over the entire flowering season ${ }^{78,55}$, we believe our proxy can provide an estimate of how the length of the flowering season may change with future warming. Additionally, a previous synthesis found that reproductive phenological events within the same species are highly correlated $^{7}$.

We compared this proxy for the duration of the community-level flowering season to the average June-July temperature at a site per year using a Bayesian hierarchical modeling approach. We mean-centered both flowering season length and average June-July temperatures for each site so we could compare the change in community-level flowering seasons with the change in June-July temperatures across sites. Because all sites chosen for these analyses had relatively long records of phenological measurements ( $>10$ years), we also examined if flowering season length or June-July temperatures have changed significantly 
over time. We analyzed associations between community flowering season length and

422 summer temperature and time with a Bayesian hierarchical model using mean-centered June-

423 July temperature as the predictor variable for the temperature sensitivity models and year as

424 the predictor variable for the temporal change models and an intercept and slope that varied

425 by site. We also examined whether mean June-July temperatures changed over time using the

426 same models with year as the predictor variable. Full model details and code are included in

427 S7.

428

429

430

431

432

433

434

435

436

437

438

439

440

441

442

443

444

445

446

\section{Data Availability Statement}

The data that support the findings of this study have been archived at the Polar Data Catalogue (data has been submitted to the Polar data catalogue - CCIN reference number 12961 -DOI will be updated when data is approved).

\section{References}

1. Fitter, A. H. \& Fitter, R. S. R. Rapid changes in flowering time in british plants. Science 296, 1689-1691 (2002).

2. Parmesan, C. \& Yohe, G. A globally coherent fingerprint of climate change impacts across natural systems. Nature 421, 37-42 (2003).

3. Thackeray, S. J. et al. Phenological sensitivity to climate across taxa and trophic levels. Nature 535, 241-245 (2016).

4. Arft, A. M. et al. Responses of tundra plants to experimental warming:meta-analysis of the international tundra experiment. Ecological Monographs 69, 491-511 (1999).

5. Høye, T. T., Post, E., Meltofte, H., Schmidt, N. M. \& Forchhammer, M. C. Rapid advancement of spring in the High Arctic. Current Biology 17, R449-R451 (2007).

6. Parmesan, C. Influences of species, latitudes and methodologies on estimates of phenological response to global warming. Global Change Biology 13, 1860-1872 (2007). 
7. Oberbauer, S. F. et al. Phenological response of tundra plants to background climate variation tested using the International Tundra Experiment. Philosophical Transactions of the Royal Society B: Biological Sciences 368, 20120481 (2013).

8. Xu, L. et al. Temperature and vegetation seasonality diminishment over northern lands. Nature Climate Change 3, 581 (2013).

9. Park, T. et al. Changes in growing season duration and productivity of northern vegetation inferred from long-term remote sensing data. Environ. Res. Lett. 11, 084001 (2016).

10. Xu, C., Liu, H., Williams, A. P., Yin, Y. \& Wu, X. Trends toward an earlier peak of the growing season in Northern Hemisphere mid-latitudes. Global Change Biology 22, 2852$2860(2016)$.

11. Bradley, N. L., Leopold, A. C., Ross, J. \& Huffaker, W. Phenological changes reflect climate change in Wisconsin. PNAS 96, 9701-9704 (1999).

12. Høye, T. T., Post, E., Schmidt, N. M., Trøjelsgaard, K. \& Forchhammer, M. C. Shorter flowering seasons and declining abundance of flower visitors in a warmer Arctic. Nature Clim. Change 3, 759-763 (2013).

13. Bjorkman, A. D., Elmendorf, S. C., Beamish, A. L., Vellend, M. \& Henry, G. H. R. Contrasting effects of warming and increased snowfall on Arctic tundra plant phenology over the past two decades. Glob Change Biol 21, 4651-4661 (2015).

14. Panchen, Z. A. \& Gorelick, R. Flowering and fruiting responses to climate change of two Arctic plant species, purple saxifrage (Saxifraga oppositifolia) and mountain avens (Dryas integrifolia). Arctic Science 1, 45-58 (2015).

15. Panchen, Z. A. \& Gorelick, R. Prediction of Arctic plant phenological sensitivity to climate change from historical records. Ecol Evol 7, 1325-1338 (2017).

16. Price, M. V. \& Waser, N. M. Effects of experimental warming on plant reproductive phenology in a subalpine meadow. Ecology 79, 1261-1271 (1998). 
17. Dunne, J. A., Harte, J. \& Taylor, K. J. Subalpine meadow flowering phenology responses to climate change: integrating experimental and gradient methods. Ecological Monographs 73, 69-86 (2003).

18. Menzel, A. et al. European phenological response to climate change matches the warming pattern. Global Change Biology 12, 1969-1976 (2006).

19. Miller-Rushing, A. J. \& Inouye, D. W. Variation in the impact of climate change on flowering phenology and abundance: an examination of two pairs of closely related wildflower species. Am. J. Bot. 96, 1821-1829 (2009).

20. Prevéy, J. et al. Greater temperature sensitivity of plant phenology at colder sites: implications for convergence across northern latitudes. Glob Change Biol 23, 2660-2671 (2017).

21. Shaver \& Kummerow, J. Arctic Ecosystems in a Changing Climate: An Ecophysiological Perspective. (Academic Press, 1992).

22. Molau, U. Relationships between flowering phenology and life history strategies in tundra plants. Arctic and Alpine Research 25, 391-402 (1993).

23. Keller, F. \& Körner, C. The role of photoperiodism in alpine plant development. Arctic, Antarctic, and Alpine Research 35, 361-368 (2003).

24. Hollister, R. D., Webber, P. J. \& Tweedie, C. E. The response of Alaskan arctic tundra to experimental warming: differences between short- and long-term responses. Global Change Biology 11, 525-536 (2005).

25. Semenchuk, P. R., Elberling, B. \& Cooper, E. J. Snow cover and extreme winter warming events control flower abundance of some, but not all species in high arctic Svalbard. Ecol Evol 3, 2586-2599 (2013).

26. Iler, A. M. et al. Maintenance of temporal synchrony between syrphid flies and floral resources despite differential phenological responses to climate. Glob Change Biol 19, $2348-2359$ (2013). 
27. Post, E., Kerby, J., Pedersen, C. \& Steltzer, H. Highly individualistic rates of plant phenological advance associated with arctic sea ice dynamics. Biology Letters 12, $20160332(2016)$.

28. CaraDonna, P. J. \& Inouye, D. W. Phenological responses to climate change do not exhibit phylogenetic signal in a subalpine plant community. Ecology 96, 355-361 (2015).

29. Körner, C. \& Basler, D. Phenology under global warming. Science 327, 1461-1462 (2010).

30. Cleland, E. E. et al. Phenological tracking enables positive species responses to climate change. Ecology 93, 1765-1771 (2012).

31. Wheeler, H. C., Høye, T. T., Schmidt, N. M., Svenning, J.-C. \& Forchhammer, M. C. Phenological mismatch with abiotic conditions_-implications for flowering in Arctic plants. Ecology 96, 775-787 (2015).

32. Inouye, D. W. Effects of climate change on phenology, frost damage, and floral abundance of montane wildflowers. Ecology 89, 353-362 (2008).

33. Wipf, S., Stoeckli, V. \& Bebi, P. Winter climate change in alpine tundra: plant responses to changes in snow depth and snowmelt timing. Climatic Change 94, 105-121 (2009).

34. Wheeler, J. A. et al. Increased spring freezing vulnerability for alpine shrubs under early snowmelt. Oecologia 175, 219-229 (2014).

35. Wheeler, J. A. et al. The snow and the willows: earlier spring snowmelt reduces performance in the low-lying alpine shrub Salix herbacea. J Ecol 104, 1041-1050 (2016).

36. Cooper, E. J., Dullinger, S. \& Semenchuk, P. Late snowmelt delays plant development and results in lower reproductive success in the High Arctic. Plant Science 180, 157-167 (2011).

37. Parsons, A. N. et al. Growth responses of four sub-arctic dwarf shrubs to simulated environmental change. Journal of Ecology 82, 307-318 (1994). 
38. Molau, U., Nordenhäll, U. \& Eriksen, B. Onset of flowering and climate variability in an alpine landscape: a 10-year study from Swedish Lapland. Am. J. Bot. 92, 422-431 (2005).

39. Grubb, P. J. The maintenance of species-richness in plant communities: the importance of the regeneration niche. Biological Reviews 52, 107-145 (1977).

40. Higgins, S. I., Delgado-Cartay, M. D., February, E. C. \& Combrink, H. J. Is there a temporal niche separation in the leaf phenology of savanna trees and grasses? Journal of Biogeography 38, 2165-2175 (2011).

41. Sanz-Aguilar, A., Carrete, M., Edelaar, P., Potti, J. \& Tella, J. L. The empty temporal niche: breeding phenology differs between coexisting native and invasive birds. Biol Invasions 17, 3275-3288 (2015).

42. Wolkovich, E. M. \& Cleland, E. E. The phenology of plant invasions: a community ecology perspective. Frontiers in Ecology and the Environment 9, 287-294 (2011).

43. Hegland, S. J., Nielsen, A., Lázaro, A., Bjerknes, A.-L. \& Totland, Ø. How does climate warming affect plant-pollinator interactions? Ecology Letters 12, 184-195 (2009).

44. McKinnon, L., Picotin, M., Bolduc, E., Juillet, C. \& Bêty, J. Timing of breeding, peak food availability, and effects of mismatch on chick growth in birds nesting in the High Arctic. Can. J. Zool. 90, 961-971 (2012).

45. Kerby, J. T. \& Post, E. Advancing plant phenology and reduced herbivore production in a terrestrial system associated with sea ice decline. Nature Communications 4, 2514 (2013).

46. Wipf, S. Phenology, growth, and fecundity of eight subarctic tundra species in response to snowmelt manipulations. Plant Ecol 207, 53-66 (2010).

47. Post, E., Pedersen, C., Wilmers, C. C. \& Forchhammer, M. C. Warming, plant phenology and the spatial dimension of trophic mismatch for large herbivores. Proceedings of the Royal Society of London B: Biological Sciences 275, 2005-2013 (2008). 
48. Schmidt, N. M. et al. An ecological function in crisis? The temporal overlap between plant flowering and pollinator function shrinks as the Arctic warms. Ecography 39, 1250$1252(2016)$.

49. Sherry, R. A. et al. Divergence of reproductive phenology under climate warming. PNAS 104, 198-202 (2007).

50. Steltzer, H. \& Post, E. Seasons and Life Cycles. Science 324, 886-887 (2009).

51. Wolkovich, E. M. et al. Warming experiments underpredict plant phenological responses to climate change. Nature 485, 494-497 (2012).

52. Prevéy, J. S. \& Seastedt, T. R. Seasonality of precipitation interacts with exotic species to alter composition and phenology of a semi-arid grassland. J Ecol 102, 1549-1561 (2014).

53. Diez, J. M. et al. Forecasting phenology: from species variability to community patterns. Ecology Letters 15, 545-553 (2012).

54. Aldridge, G., Inouye, D. W., Forrest, J. R. K., Barr, W. A. \& Miller-Rushing, A. J. Emergence of a mid-season period of low floral resources in a montane meadow ecosystem associated with climate change. Journal of Ecology 99, 905-913 (2011).

55. CaraDonna, P. J., Iler, A. M. \& Inouye, D. W. Shifts in flowering phenology reshape a subalpine plant community. PNAS 111, 4916-4921 (2014).

56. Cook, B. I. et al. Sensitivity of spring phenology to warming across temporal and spatial climate Gradients in Two Independent Databases. Ecosystems 15, 1283-1294 (2012).

57. Høye, T. T. et al. Phenology of high-arctic butterflies and their floral resources: Speciesspecific responses to climate change. Curr Zool 60, 243-251 (2014).

58. Hocking, B. Insect-flower associations in the high arctic with special reference to nectar. Oikos 19, 359-387 (1968).

59. Janzen, D. H. Synchronization of sexual reproduction of trees within the dry season in central america. Evolution 21, 620-637 (1967). 
60. Meng, F. D. et al. Changes in flowering functional group affect responses of community phenological sequences to temperature change. Ecology 98, 734-740 (2017).

61. Hulme, P. E. Contrasting impacts of climate-driven flowering phenology on changes in alien and native plant species distributions. New Phytologist 189, 272-281 (2011).

62. Körner, C. \& Basler, D. Plant science. Phenology under global warming. Science 327, 1461-1462 (2010).

63. Craine, J. M., Wolkovich, E. M., Gene Towne, E. \& Kembel, S. W. Flowering phenology as a functional trait in a tallgrass prairie. New Phytologist 193, 673-682 (2012).

64. Miller-Rushing, A. J., Høye, T. T., Inouye, D. W. \& Post, E. The effects of phenological mismatches on demography. Philosophical Transactions of the Royal Society B: Biological Sciences 365, 3177-3186 (2010).

65. Elmendorf, S. C. et al. Experiment, monitoring, and gradient methods used to infer climate change effects on plant communities yield consistent patterns. PNAS 112, 448452 (2015).

66. Hollister, R. D. et al. Warming experiments elucidate the drivers of observed directional changes in tundra vegetation. Ecol Evol 5, 1881-1895 (2015).

67. Molau, U. \& Mølgaard, P. International tundra experiment (ITEX) manual. Danish Polar Center, Copenhagen, Denmark (1996).

68. Henry, G. h. r. \& Molau, U. Tundra plants and climate change: the International Tundra Experiment (ITEX). Global Change Biology 3, 1-9 (1997).

69. Harris, I., Jones, P. d., Osborn, T. j. \& Lister, D. h. Updated high-resolution grids of monthly climatic observations - the CRU TS3.10 Dataset. Int. J. Climatol. 34, 623-642 (2014).

70. Marion, G. m. et al. Open-top designs for manipulating field temperature in high-latitude ecosystems. Global Change Biology 3, 20-32 (1997). 
597 71. Hollister, R. D., Webber, P. J., Nelson, F. E. \& Tweedie, C. E. Soil Thaw and

598 Temperature Response to Air Warming Varies by Plant Community: Results from an

599 Open-top Chamber Experiment in Northern Alaska. Arctic, Antarctic, and Alpine

$600 \quad$ Research 38, 206-215 (2006).

601 72. Walker, M. D. et al. Plant community responses to experimental warming across the 602 tundra biome. PNAS 103, 1342-1346 (2006).

603 73. Latimer, A. M. Geography and Resource Limitation Complicate Metabolism-Based

604 Predictions of Species Richness. Ecology 88, 1895-1898 (2007).

605 74. Stan Development Team. Stan Modeling Language Users Guide and Reference Manual, $606 \quad$ Version 2.17.0. (2017).

607 75. Stan Development Team. RStan: the R interface to Stan. R package version 2.17.3.

$608 \quad$ (2018).

609 76. R Core Team. R: A language and environment for statistical computing. (2017).

610 77. Gelman, A. \& Rubin, D. B. Inference from Iterative Simulation Using Multiple

611 Sequences. Statistical Science 7, 457-472 (1992).

612 78. Miller-Rushing, A. J., Inouye, D. W. \& Primack, R. B. How well do first flowering dates

613 measure plant responses to climate change? The effects of population size and sampling

614 frequency. Journal of Ecology 96, 1289-1296 (2008).

615

616

617

618

619

620

621

622

623 


\section{Acknowledgements}

We are grateful to the many individuals who established experiments and collected detailed phenological observations, there are too many to name them all, however, we want to especially thank Michele Dalle Fratte, Dorothy Cooley, Orin Durey, Cameron Eckert, Jill F. Johnstone, Catherine Kennedy, Vincent Lamarre, Guylaine Levasseur, Carmen Spiech, Josef Svoboda, Renee Wising, the Herschel Island - Qikiqtaruk Territorial Park staff including Edward McLeod, Samuel McLeod, Ricky Joe, Paden Lennie, Deon Arey, LeeJohn Meyook, Jordan McLeod, Pierre Foisy, Colin Gordon, Jeremy Hansen, Albert Rufus, and Richard Gordon, Quttinirpaaq National Park staff, the Greenland Ecosystem Monitoring team, WARM coordinators Nathan Sanders, Aimee Classen, and Maja Sundqvist, and others. These observations were made possible with the support of many funding agencies and grants including: ArcticNet, the Natural Sciences and Engineering Council of Canada, Canadian International Polar Year Program, Polar Continental Shelf Program of Natural Resources Canada, the Danish Environmental Protection Agency, the Swiss Federal Institute for Forest, Snow, and Landscape Research WSL, The National Geographic Society, US National Science Foundation grant numbers: PLR 1525636, PLR 1504141, PLR 1433063, PLR 1107381, PLR 0119279, PLR 0902125, PLR 0856728, PLR 1312402, PLR 1019324, LTER-1026415, 1433063, 0856728, 0612534, 0119279, 9421755, OPP 1525636, OPP-9907185, 0856710, 9714103, 0632263, 0856516, 1432277, 1432982, 1504381, and 1504224, DEB -1637686, Danish National Research Foundation grant:

CENPERM DNRF100, Danish Council for Independent Research - Natural Sciences grant: DFF 418100565, Deutsche Forschungsgemeinschaft grant: RU 1536/3-1, Natural Environment Research Council grant: NE/M016323/1, Department of Energy grant: SC006982, a Semper Ardens grant from the Carlsberg Foundation to N. J. Sanders, and an INTERACT Transnational Access grant.

\section{Author contributions}

J.P. and C.R. designed and led the manuscript; J.P. and C.R. led the collection of the phenology database; J.P., N.R., A.B., I.M.S. and S.E performed statistical analyses; J.P., C.R., N.R., T.H., A.B., I.M.S. and S.E drafted the paper; J.P., C.R., A.B., I.M.S., I.A., N.C, C.C., E.C., B.E., A.M.F, G.H., R.H., I.S.J., K.K., C.K., E.L., M.M., U.M., S.N., S.O., Z.P., E.P., S.R., N.M.S., E.S., P.S, J.S, K.K, Ø.T., T.T., S.V., C. W., J.W., and S.W. contributed data; and all authors were involved in writing and editing the manuscript. 
654 Competing Interests

655

656 The authors declare no competing interests. 
Fig. 1. Conceptual diagram showing how warmer summer temperatures may shorten the length of the flowering season in tundra ecosystems. If the phenology of early-flowering plant species is influenced primarily by photoperiod or the timing of snowmelt and does not respond appreciably to warmer summer temperatures, but the phenology of late-flowering species is mostly dependent on accumulated heat sums over the growing season, and does shift earlier with warmer summers, then there may be a contraction of the overall flowering season during warmer years.

Fig. 2. Map of long-term observational and experimental warming studies. Site names are listed in order from the site with the coldest $\left(2.8^{\circ} \mathrm{C}\right)$ to the site with the warmest $\left(11.9^{\circ} \mathrm{C}\right)$ summer temperatures (June-Aug. for northern hemisphere sites, Dec-Feb. for the southern hemisphere site, Supplementary Fig. 1). Site symbols shown on the map correspond to symbols and colors in Figs. 3-4. Asterisks indicate sites used in community flowering season analyses.

Fig. 3. Temperature sensitivity of first flowering dates (FFDs) was greater for late- versus earlyflowering species. Relationships are shown between phenological niches of species and sensitivities of FFDs to (a) mean monthly temperature until flowering (b) mean June temperature (c) mean daily temperature between the snowmelt and flowering, and (d) the date of snowmelt. Points represent the estimated temperature sensitivities for each species at each site, and vertical gray lines span the $95 \%$ credible intervals for each species-by-site level estimate. Colors and symbols correspond to site names in Fig. 2. The 'phenological niche' is the average flowering date of a species compared to the site-level mean-flowering date of all species at a site. Solid black lines denote significant hierarchical model slopes, dashed black lines indicate non-significant model slopes, and the horizontal grey line denotes the zero line. Hierarchical model slopes and 95\% credible intervals (CIs) are listed in the bottom left of each graph. The phenological niches significantly predict phenological responses (at the $5 \%$ level) if the $95 \%$ credible intervals do not overlap zero.

Fig. 4. The change in first flowering dates (FFDs) in response to experimental warming was greater for late- versus early-flowering species. Relationships are shown between phenological niches of species and timing of (a) FFDs and (b) Last flowering dates (LFDs) in experimentally warmed plots compared to control plots. Points represent the estimated temperature sensitivities for each species at each site, and vertical gray lines span the $95 \%$ credible intervals for each species-by-site level estimate. Colors and symbols correspond to site names in Fig. 2. The 'phenological niche' is the average flowering date of a species compared to the site-level mean-flowering date of all species at a site. Solid black lines denote significant hierarchical model slopes, dashed black lines indicate nonsignificant model slopes, and the horizontal grey line denotes the zero line. Hierarchical model slopes and $95 \%$ credible intervals (CIs) are listed in the bottom left of each graph. The phenological niches significantly predict phenological responses (at the 5\% level) if the $95 \%$ credible intervals do not overlap zero.

Fig. 5. Warming was related to the change in the duration of the flowering season over time at sites across the tundra biome. (a) Difference in the duration of the community level flowering season compared to the difference in mean June-July temperatures from site averages. (b) Change in the duration of the community level flowering season over time. (c) Yearly June-July temperature over time. Flowering season length and average June-July temperatures were mean-centered for each site so they could be compared across sites. Points represent the change in the community-level flowering season per site and year. Solid black lines denote significant hierarchical model slopes, and dashed black lines indicate non-significant model slopes. Colored bands show the $95 \%$ credible intervals for site-level slopes. Hierarchical model slopes and 95\% credible intervals (CIs) are listed in the bottom left of each graph. 


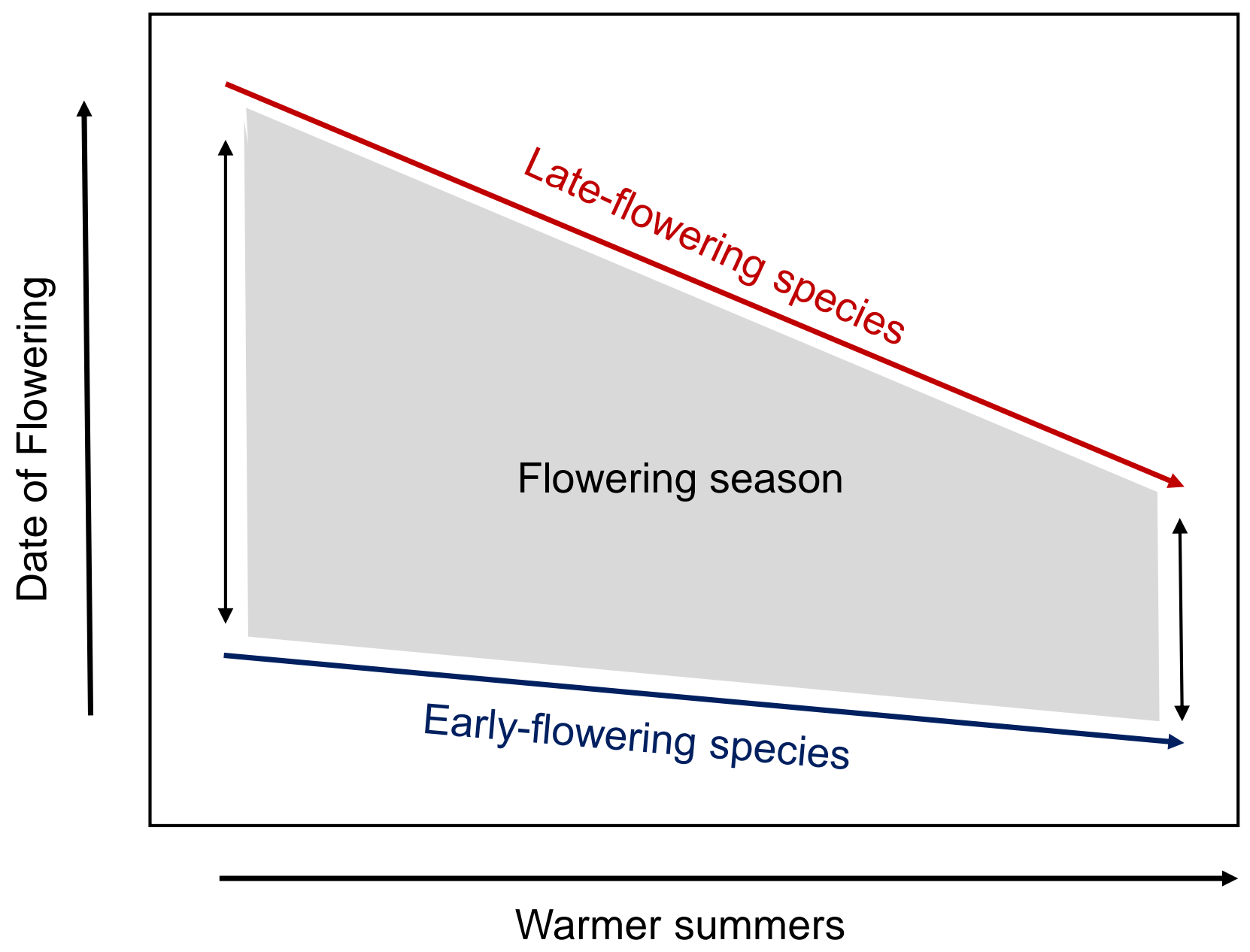




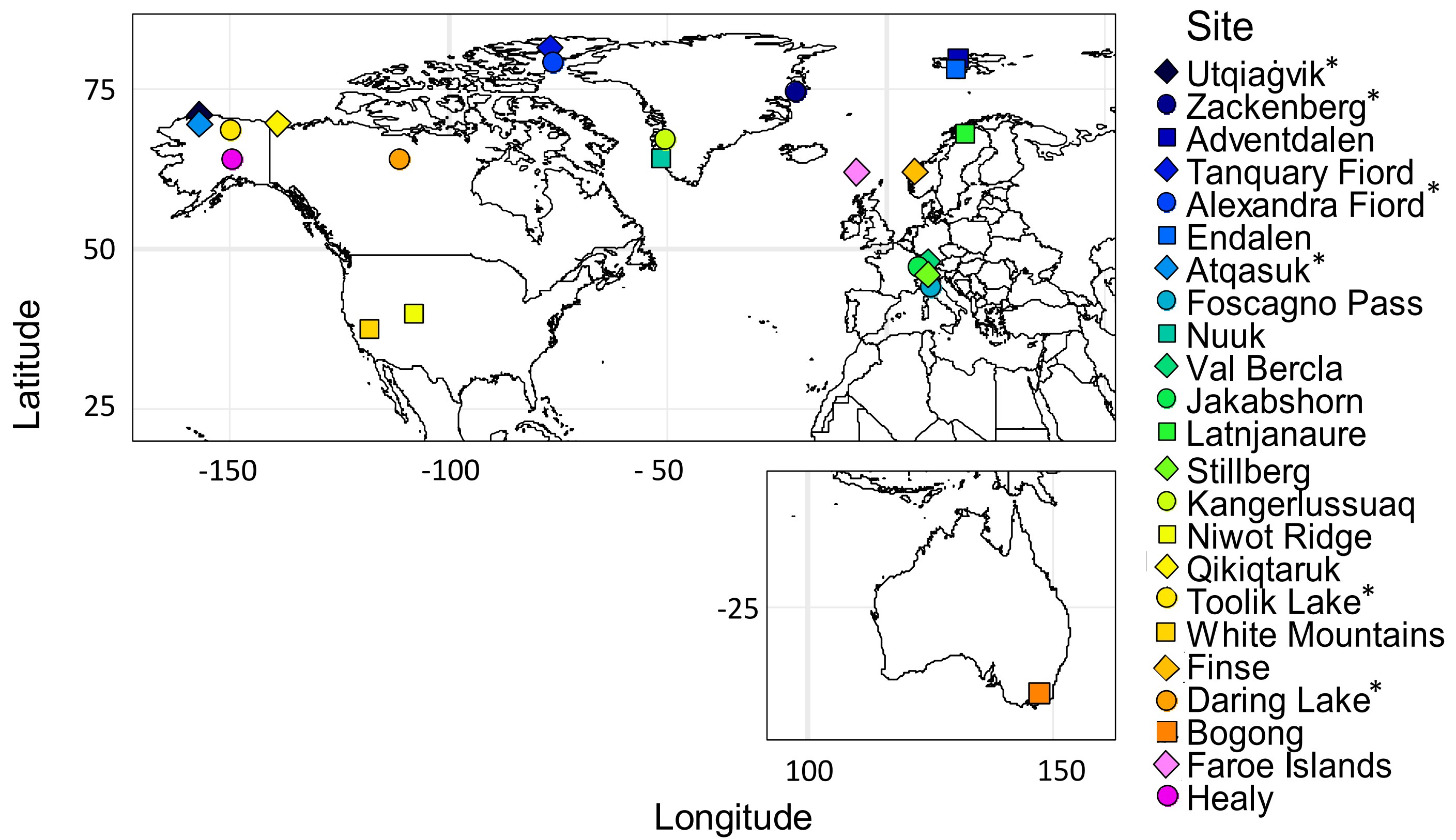



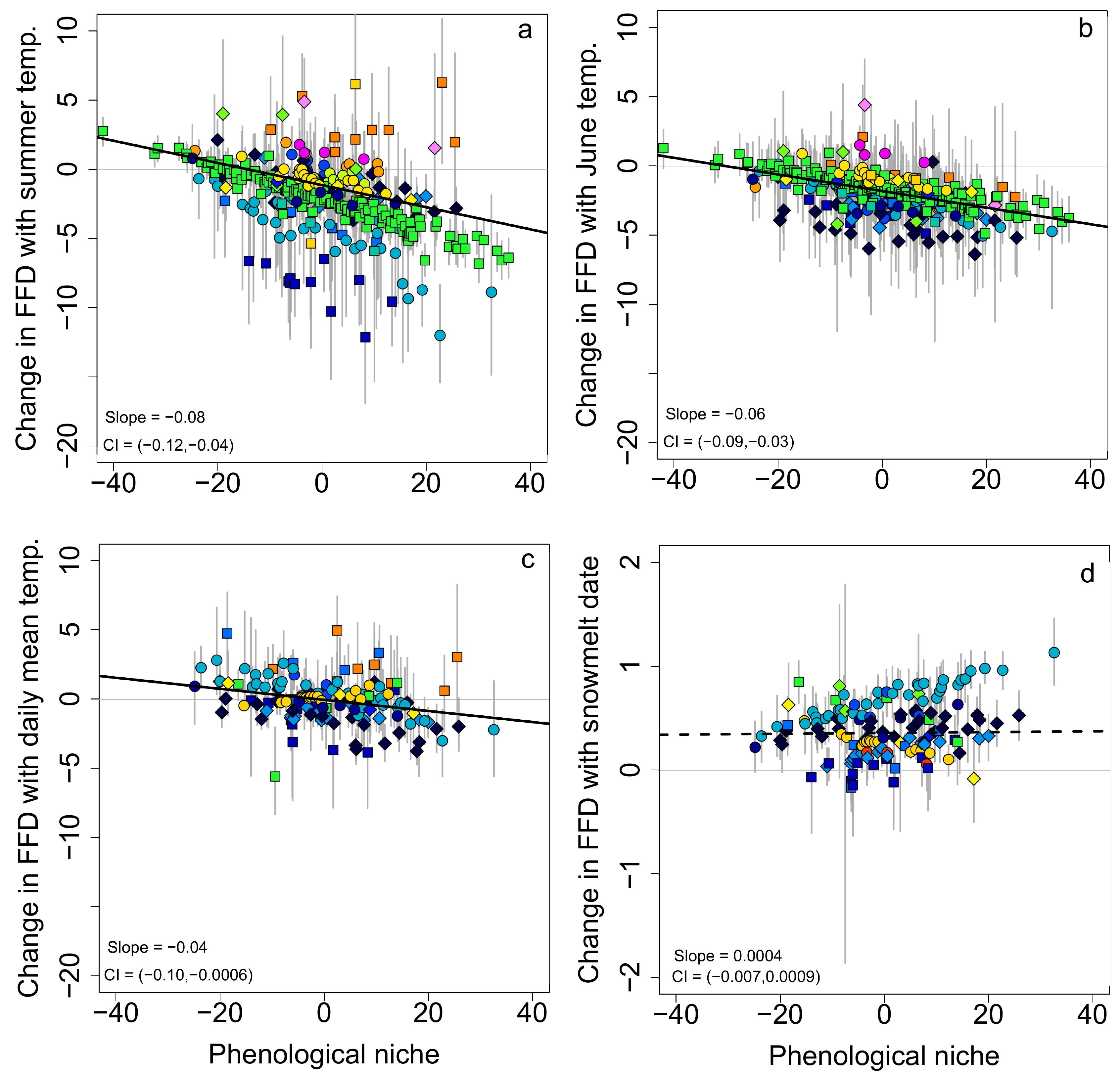

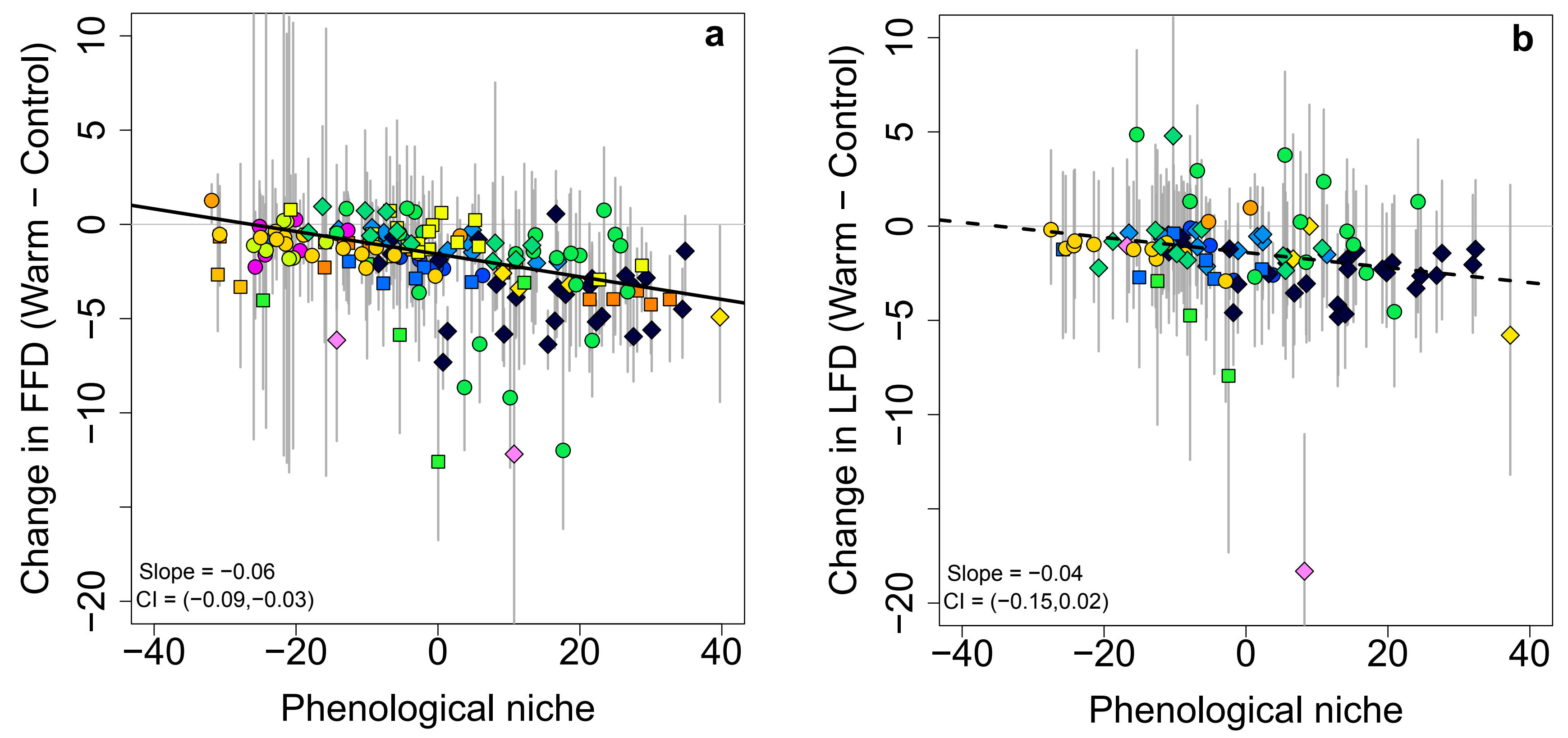


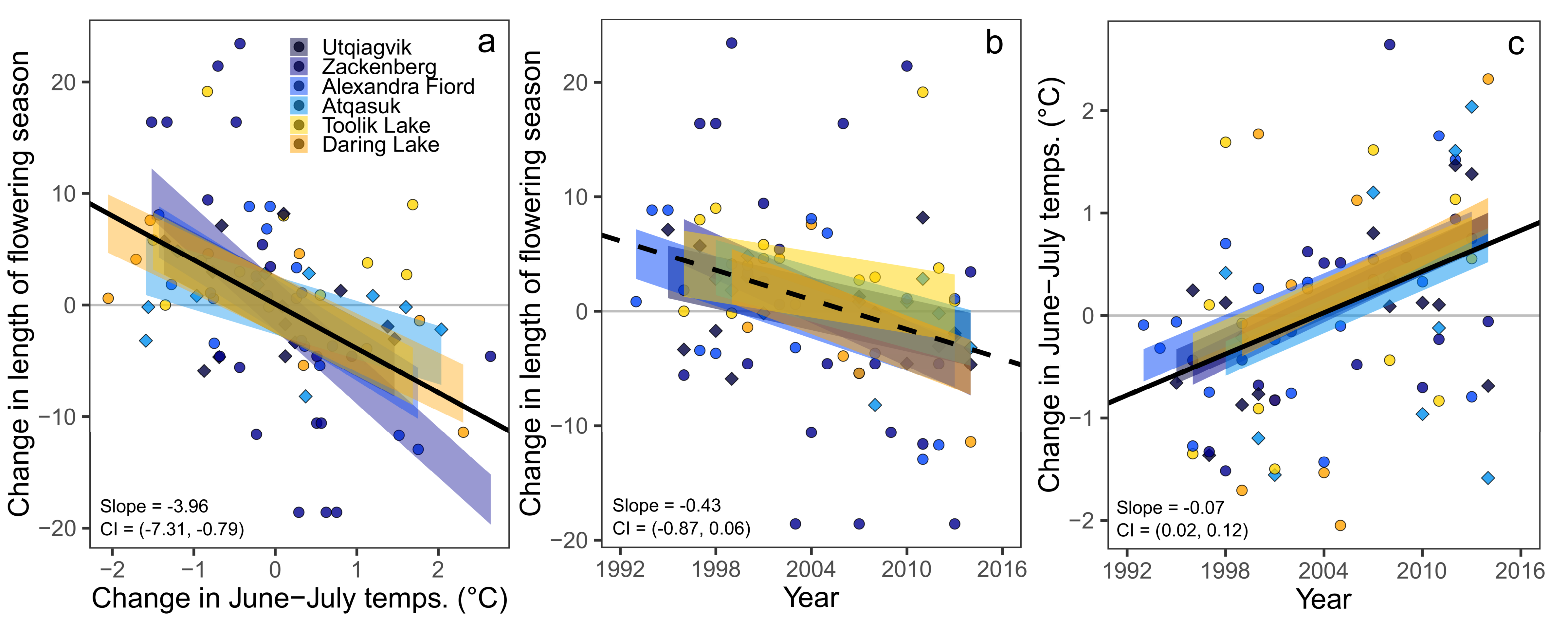

